\title{
Monetary Policy Rules for Transition Economies: An Empirical Analysis
}

\author{
Subrata Ghatak ${ }^{1}$ and Tomoe Moore ${ }^{2}$
}

October, 2008

$1 \quad$ School of Economics, Kingston University, Penrhyn Road, Kingston upon Thames, Surrey KT1 2EE, United Kingdom, Tel: +44 116 2707415, S.Ghatak@ kingston.ac.uk.

2 Department of Economics and Finance, Brunel University, Uxbridge, Middlesex, UB8 3PH, United Kingdom, Tel: +44 189526 7531, tomoe.moore@brunel.ac.uk 


\title{
Monetary Policy Rules for Transition Economies: \\ An Empirical Analysis
}

\begin{abstract}
In this paper, we innovatively apply both Taylor rule, where an interest rate is used as a policy reaction, and McCallum rule, where monetary base is considered as a policy instrument, for the new EU member states in analysing monetary policy reaction functions. For the Czech Republic, Poland, Slovakia and Slovenia, the Taylor rule is found to be suitable to exchange rate targeting, whereas the McCallum rule may be applicable to inflation targeting. Evidence also reveals that for Hungary and Romania, inflation targeting coexists with that of exchange rates taking account of both reactions of interest rates and money.
\end{abstract}

Keywords: Monetary policy reaction functions, Taylor Rule, McCallum's Rule, Transition economies

JEL Classification: E4, E5, O57 


\section{Introduction}

In the recent literature on the control of inflation in macroeconomics, the use of Taylor Rule has gained wide attention (see, e.g. Taylor 1993, 1999 and 2007, Sánchez-Fung 2005, Woodford 2004 and Ghatak and Sánchez-Fung 2007). Such type of attention is understandable in the light of the claims that inflation is the ultimate 'judge and the jury' of the eventual success of a prudent macroeconomic policy for economic stabilisation and growth. In emerging economies of new European Union (EU) member countries including Romania and Bulgaria which have recently joined the EU, not only the control of inflation, but also the stability of exchange rates might have been the components of major factors in achieving full integration with the economies of Western Europe. In this context, little attention has been paid so far about the efficacy of using the Taylor Rule as a policy variable though attention has been paid to the role of inflation targeting in some of the transition economies (TE). There is also one another issue to be noted in the monetary policy analysis in TE. How should the stance of monetary policy measured? Most observers emphasize interest rates, whereas the traditional monetary approach stresses monetary aggregate, for example the domestic credit component of the monetary bases was deemed to be the variable controlled by policy makers. The empirical emphasis has been on interest rates, and there is an acute negligence of the latter in the literature.

In this paper, we aim to examine the monetary policy reaction functions based on the hypotheses of Taylor rule, where an interest rate is used as a reaction function, and McCallum rule, where monetary aggregate matters as a policy tool ${ }^{3}$ in the conduct of stabilising main macroeconomic variables including both inflation and exchange rates for the transition economies of the Czech Republic, Hungary, Poland, Slovakia, Slovenia, Bulgaria and Romania during the sample period of around 1994 to 2006.

3 We use the term 'McCallum rule' (McCallum 1987 and 1988) in order to contrast with the Taylor rule. 
In general, theoretical and empirical literature of the monetary policy reaction function has been addressed mainly for developed countries. There is a very limited work conducted for developing economies, for example, Frömmel and Schobert (2006) studied a variation of Taylor rule by adopting forward looking elements put forward by Clarida et al. (1998) for the Central and Eastern European countries over the period of 1994-2003. See also, Schmidt-Hebbel and Tapia (2002) for Chile and Shortland and Stasavage (2004) for the West Africa economies. These studies follow those for developed economies with a shortterm interest rate as a policy rule to determine the monetary policy reaction function ${ }^{4}$. Unlike developed countries, in emerging markets the transmission mechanism through the channel of interest rates may be sluggish due to underdeveloped financial markets, hence it raises a question of relying solely on a similar type of model based on the Taylor's rule to transition economies for the policy analysis.

The main motivation of writing this paper is to examine whether the TEs mainly followed the Taylor rule or the McCallum-type rule as an instrument of monetary stabilisation. To the best of our knowledge, such a comparative analysis has not been attempted before. Although, the recent work for Dominican Republic by Sánchez-Fung (2005) developed a hybrid monetary policy reaction based on the McCallum rule with money as a monetary policy instrument, Sánchez-Fung did not explore the interest rate policy rule.

We have modelled a monetary policy function by carefully checking any structural shift in estimates by the likelihood test and the parameter stability by the Chow forecast test. Our main empirical finding is that, in this broader criterion, monetary aggregate were more likely to react to the deviation of inflation to its long-run level, whereas short-term interest rates

\footnotetext{
$4 \quad$ In the work of Savvides (1998) for West and Central African countries, the fixed exchange rate arrangements was explained as a monetary policy behaviour by specifying the variables of foreign reserves and domestic credit to the government.
} 
were highly sensitive to the deviation of exchange rates from the potential level, except for Hungary and Romania, where inflation targets were found to coexist with that of exchange rates taking account of both reactions of interest rates and money.

The plan of this paper is as follows. Theoretical review is found in Section 2. Data, unit root test and structural test are found in Section 3. Section 4 is for the empirical estimation of the alternative hypotheses, and Section 5 presents dynamic responses by utilising the impulse response function. Section 6 is for the concluding remarks.

\section{Theoretical Review}

\subsection{Policy rule with the interest rate or monetary aggregate as the instrument}

The main type of monetary policy suggested in the early 1990s to control inflation was the Taylor rule, which was originally designed for the USA, but also worked well in G7 economies. These economies are assumed to have both a fully developed long term bond market and a foreign exchange market with a high degree of capital mobility. The Taylor rule (Taylor 1993 and 1999) is generally defined by:

$$
r=r^{*}+\beta\left(\pi-\pi^{*}\right)+\gamma\left(y-y^{*}\right)
$$

where $r$ : the actual nominal short term interest rate, $r^{*}:$ the equilibrium nominal short term interest rate, $\pi$ : the actual rate of inflation, $\pi^{*}:$ the equilibrium rate of inflation, $y$ : the actual output and $y^{*}$ : the capacity output. A question that arises is if the Taylor rule is also a useful guide for monetary policy in TEs. Note that the Taylor rule does not take direct account of shocks, which one would expect to occur more prominently in TEs than in developed economies. Still, it may be argued that Taylor rules have many of the same advantages in TEs as they have in developed countries. In particular, for TEs that do not 
always choose a policy of a 'permanently' fixed exchange rate (perhaps through a currency board or through a common currency, e.g. dollarisation in Bulgaria), a sound monetary policy could be based on the trinity of a flexible exchange rate, an inflation target, and a monetary policy rule. But it will be necessary to change some of the features of the typical kind of policy rule that is recommended for countries with more developed financial markets.

In the context of our analysis, the Taylor rule describes the change in the instruments that would accompany an increase in inflation or in real GDP relative to potential GDP. The instrument has been a short term overnight interest rate. But other instruments in a policy rule could be the money base, or some other monetary aggregate. Although earlier Taylor (1979) uses money supply as the instrument, McCallum (1988) explicitly put forward advantages of policy rules with a monetary aggregate as the instrument and the famous Friedman growth rate rule also has a monetary aggregate as the instrument. Thus, we consider McCallum rule as an alternative to Taylor rule to take these considerations into account. Put simply, McCallum (1988) argues in favour of manipulating the monetary base to control inflation. Indeed, McCallum's (1987 and 1988) monetary base rules can be written as:

$$
\Delta h_{t}=\alpha-\Delta v_{t}+\delta\left(y_{t}-y_{t}{ }^{*}\right)
$$

$h$ is the monetary base, $\alpha$ is a constant term, $y$ is the log of nominal output, $y_{t}^{*}$ is the target value and $v_{t}$ is the velocity of monetary base. A parameter, $\delta$, indicates the speed at which deviations of output reach its target value with the policy instrument (Ghatak and SanchezFung 2007). McCallum (1987) found that this would have been suitable in terms of smoother GNP path after comparing simulations using this with actual policy reactions.

The following consideration determines the choice between a policy rule with the interest rate as the instrument and a policy rule with the money base (or some other monetary aggregate) as the instrument. If there is too much uncertainty in measuring the real interest 
rate or if there are relatively big shocks to investment or net exports, then a monetary aggregate is the preferred instrument. The same is true if it is difficult to measure the equilibrium real interest rate. But if velocity shocks are big, then the interest rate is the more suited instrument. The preference for the interest rate instrument in recent works on policy rules primarily reflects velocity uncertainty - a major concern in many TEs particularly when money demand function is unstable during a period of structural change and transformation of the economies. But there are circumstances where real interest rate measurement is difficult. Such cases may very well be present in TEs. In a situation of a high growth rate and/or a high inflation rate, the real interest rate is hard to measure, and the risk and ambiguity premia can be high and variable, e.g. due to the presence of political uncertainty (Svensson 2003, Greenspan 2004 and Ghatak and Spanjers 2007) ${ }^{5}$. Moreover, if the government experiences high fiscal deficits, nominal interest rates are often administered in a way that governments can borrow cheap from the market, as often found in developing economies. With an interest rate rule, uncertainty about the equilibrium real interest rate can translate into policy errors. Policy makers in TEs might want to give greater consideration to policy rules with monetary aggregates, even if rules with the interest rate become the preferred choice.

\subsection{Inflation and exchange rate targetings}

One of the popular application of the Taylor rule is inflation targeting. Having an inflation target is essential for good monetary policy making in cases where a country decides on a

\footnotetext{
5 It is argued that the nominal interest rate may fail to be the appropriate instrument in such rules. The extent of political and economic risks inherent in transition economies is not measurable, yet these risks may lead to a significant and volatile-ambiguity premium in the interest rate over and above the normal risk premium. This makes the real equilibrium interest rate difficult to measure (Ghatak and Spanjers 2007).
} 
flexible exchange rate regime. The inflation target places the nominal anchor on domestic prices. In this it contrasts with a fixed exchange rate regime, a currency board, or dollarization. The increased focus on the inflation target in TEs is a welcome development. By the target rate of inflation we mean the value level of inflation that one would like to be the one that the actual inflation rate fluctuates around. The inflation targeting rule is:

$$
r_{t}=\rho_{r} r_{t-1}+\left(1-\rho_{r}\right) \beta\left(\pi_{t}-\pi^{*}\right)+\varepsilon_{m t}
$$

where $\rho_{r}$ is the interest rate smoothing parameter, and $\varepsilon_{m t}$ denotes a domestic monetary policy shock. Appendix 1 provides an impression of the inflation targets of some countries that operate an inflation targeting regime. The Taylor rule extends the inflation targeting rule by adding the deviation of output from its capacity:

$$
r_{t}=\rho_{r} r_{t-1}+\left(1-\rho_{r}\right) \beta\left(\pi_{t}-\pi^{*}\right)+\left(1-\rho_{r}\right) \gamma\left(y_{t}-y^{*}\right)+\varepsilon_{m t}
$$

A central bank may want to implement a general interest rate rule in order to achieve specific policy objectives. Such rule may take the adjustment in exchange rates, as a policy variable, and this is obtained by adding a reaction to the devaluation of the exchange rate, as exchange rate volatility is a cause for worry to many countries. The rule is

$$
r_{t}=\rho_{r} r_{t-1}+\left(1-\rho_{r}\right) \beta\left(\pi_{t}-\pi^{*}\right)+\left(1-\rho_{r}\right) \gamma\left(y_{t}-y^{*}\right)+\left(1-\rho_{r}\right) \delta\left(e_{t}-e^{*}\right)+\varepsilon_{m t}
$$

where $e_{t}$ denotes the exchange rate and $e^{*}$ is its' target level. This reflects the concern of the sustainability of the purchasing power of the domestic currency together with price stability and output growth. This is particularly important for emerging markets, as typically central banks appears to be mindful of external factors and the foreign exchange value of their currency (Calvo and Reinhart 2002).

The actual short term interest rate as set by the central bank may, however, at times deviate from the one indicated by the appropriate policy rule, as some special factors of the 
policy environment cannot be included in the rule. Liquidity crises in financial markets will usually require such discretion. For example, before the 1987 and 2008 when stock market fell respectively in the USA, the Fed was increasing the short term interest rate, apparently because inflation and the output gap were increasing. But when liquidity became a concern after the crash, the Fed lowered the interest rate and thereby provided more liquidity. The size of the interest rate responses in policy rules matter greatly for economic performance. Changing the interest rate by more than one for one with inflation is a crucial property of a good monetary policy rule. A response that is smaller than one-to-one can result in very poor performance ${ }^{6}$.

Adapting the McCallum's equation (2), the policy rule with monetary aggregate can be specified as the instrument ${ }^{7}$ :

$$
\Delta h_{t}=B+\delta\left(y_{t}-y^{*}\right)+\theta\left(\pi_{t}-\pi^{*}\right)+\psi\left(e_{t}-e^{*}\right)+\varepsilon_{m t}
$$

where the first term implies the output gap from the target value, the second term, inflation gap and the third term, the exchange rate gap. $\delta, \theta$ and $\psi$ are the parameters. It is probable that the interest rate channel of the monetary policy transmission mechanism on the price level is sluggish owing to the underdeveloped capital and money market, therefore it is of less importance, whereas money aggregate may be playing a more central role in inflation targeting for emerging economies ${ }^{8}$.

6 An example of this is the USA's response of the interest rate to inflation in the late 1960s and the 1970s in comparison with the 1980s and 1990s.

$7 \quad$ See also Sanchez-Fung (2005), who used a hybrid McCallum-Taylor monetary policy reaction function for a developing country.

8 In industrial economies, interest rates provide much of the fundamental and timely information on the economy, to which the policy is directed. On the other hand, in emerging economies where the markets are 
Our empirical analysis is based on the Taylor's equation (5) and the McCallum's equation (6).

\section{Data, unit root tests and structural break tests}

Aggregate monthly data are used for the seven countries of the Czech Republic, Hungary, Poland, Slovakia, Slovenia, Bulgaria and Romania. The sample period starts from $1994 \mathrm{~m} 1$ to 2006m12 with 156 observations, except for the Czech Republic starting 1995m12 onward (133 observations), for Hungary, 1995m1 onward (144 observations) and Bulgaria, 2000m1 onward (84 observations) due to data availability. Data are collected from the International Financial Statistics and Datastream. The details of the data and the descriptive statistics are found in Appendix 2 and 3. The variables of GDP ( $g d p)$, money $(m)$ and exchange rates $(e x)$ are in logarithmic from. Note that the CPI is used for inflation. Although it includes regulated prices in the basket in TEs, it is well understood to public in the emerging economies (Amato and Gerlach 2002) ${ }^{9}$.

In order to derive a smooth estimate of the long-run trend component of a series, i.e. the approximation of the equilibrium variable of $y^{*}, \pi^{*}$ and $e^{*}$, the Hodrick-Prescott filter, which smooth series by minimising the variance of the series, is utilised. The integer value for the smoothing parameters is chosen to be at 14,400, suggested by Hodrick and Prescott (1997) for the monthly data.

more likely to be fragmented and yet governed, interest rates do not particularly function as a transmission mechanism. In this case, the quantities in money would be used in the formation of inflation targeting policy (Moore et al. 2006).

9 There is no independent measure of CPI, which separates regulated prices from the basket except for the Czech Republic (Amato and Gerlach 2002). 
The stationary property of each variable is examined by the unit root test. We conduct the Augmented Dickey-Fuller (ADF) tests together with the Phillips Perrons (PP) test (Phillips 1987). The PP test is a variant of ADF based on the Z-test. While the DickeyFuller procedure retains the validity of tests based on white-noise errors in the regression model, the PP test involves a non-parametric correction to the test statistic to account for the serial correlation in residuals, and produces statistics that are robust to heteroskedasticity (Banerjee et al. 1993) ${ }^{10}$. The test results are found in Table 1 with the notations of nominal interest rates $(r)$, inflation gap $\left(g i n f l=\pi-\pi^{*}\right)$, GDP gap $\left(g g d p=y-y^{*}\right)$, exchange rate gap $\left(g e x=e-e^{*}\right)$ and money $(m)$. Where variables are found to contain a unit root, the test is conducted by differencing the variables.

Deviations of inflation ( $g i n f l)$, GDP ( $g g d p)$ and exchange rates (gex) appear to follow a stationary process in their levels in either test, since the null of unit root is mostly rejected at the conventional significance level. Four cases in the ADF test, i.e. ginfl in Hungary, ggdp and gex in Bulgaria and ggdp in Romania are not rejected, though the PP test rejects the null of these variables. Since the PP test generally has higher power, we treat these variables as stationary. In terms of the time series of $r$ and $m$, the test statistics are largely in favour of non-stationary, and their first differences are shown to be stationary ${ }^{11}$.

In light of the unit root test results, the series of $r$ and $m$ are specified in first differences to avoid spurious regression, whereas ginfl, ggdp and ggex are specified in levels.

\footnotetext{
10 Although the PP test has poor sample size properties, given a reasonably large sample size in our study, it should not be a concern.

11 The exceptions are $m$ in Slovenia, where the both tests reject the null of unit root in level and that the variable appears to be stationary. In order to pursue uniformity in estimation across these countries, we, however, first-difference the $m$ for estimation.
} 
Based on the models (5) and (6), the model specifications for empirical estimation are given by respectively:

$\Delta r=\alpha+\beta_{0} \Delta r_{t-1}+\beta_{1} \operatorname{ginfl}_{t}+\beta_{2} g g d p_{t}+\beta_{3} \operatorname{gex}_{t}+u_{t}$

$\Delta m=\mu+\eta_{0} \Delta r_{t-1}+\eta_{1} g \operatorname{ginfl}_{t}+\eta_{2} g g d p_{t}+\eta_{3} g e x_{t}+u_{t}$

where the model (7) is associated with the Taylor rule and the model (8), with the McCallum rule.

The Central Eastern European stock markets have gone through phases of domestic and international shifts in the process of transition from command to market economy. In order to examine the possibility of exogenous shifts in the model, the significance of specificevents is tested. The event dummies are listed in the notes of Table 2. Each dummy is specified one by one based on the models (7) and (8) for the likelihood ratio test with the OLS. The results are presented in Table 2.

The period and shift dummies (D1 and D2) of the Asian and Russian crises are found to be significant in six cases, suggesting a contagion effect on the monetary policy reaction in these transition economies. The dummies for inflation targeting in the Czech Republic (D3) in the interest rate equation and in Poland (D2) in the money equation are significant, which is indicative of a policy shift. The impact of entry to the EU (D9) is only found in Slovenia. This is intuitively plausible, since Slovenia is the only new EU member states, who joined ERM II ${ }^{12}$.

The significant dummies found in the likelihood test are all, initially, specified in the model. However, evaluating each dummy separately introduces the problem of specification bias and tends to lead to increased significance for each dummy. We have, therefore, further checked the significance of the dummy in the process of estimation in Section 4.

\footnotetext{
12 The Maastricht exchange rate criterion implies a participation in the ERM II for new EU countries as a prerequisite for joining the single currency. Slovenia opted for the ERM II in 2004.
} 


\section{Estimation}

Since there is potentially an endogeneity problem among dependent and independent variables in the models, the instrument variable (IV) method is utilised. The instrument variables are the lagged once and twice dependent variables and regressors, which are orthogonal to the disturbances.

The estimation method takes two steps. First, we run a regression for the models using the IVs by specifying the event and policy dummies and monthly dummies. We only retain the event and policy dummies if they are significant at the $5 \%$ level by the t-statistics, otherwise dummies are deleted from the model. We then check the plot of residuals to see if there is any spike of the series, from which pulse dummies are determined ${ }^{13}$, which improves the fitness of the model. We then re-run the regression with the statistically significant pulse dummies. The estimation results are found in Table 3.

Diagnostic tests for serial correlation by the Breusch-Godfrey test are, in general, satisfactory. Heteroskedasticity test by the Breusch-Pagan-Grodrey method indicates that some of the residuals tend to reject the null of homoskedasticity. This is corrected using robust estimation with the White's heteroskedastic consistent t-ratios. The Ramsey RESET test appears to suggest little presence of specification errors, as the statistics are mostly insignificant at the $5 \%$ level.

These transition economies have undergone substantial changes in the estimation period, and that we further carried out a series of Chow forecast tests to examine the parameter stability by checking slope coefficients for breaks (Bai 1996). We chose 5 potential breakpoints (one every two years) making 5 tests in each equation. The results are

13 We take a dummy 1 where there is a spike in residuals and 0 otherwise. 
shown in Table 4. There is evidence of a break in just 8 out of 70 cases at the $5 \%$ significance level. Slovenia has shown to be statistically significant in three cases in $\Delta m$ equation, hence we have checked the separate slope coefficients across breaks, see the notes for Table 4. It is found that only those coefficients for the break point of $2000 \mathrm{~m} 12$ (i.e. the forth column, from $1994 \mathrm{~m} 1$ to $2000 \mathrm{~m} 11$ ) considerably deviate from others. Overall though, these diagnostics suggest that the underlying parameter estimates are remarkably robust ${ }^{14}$.

For the Czech Republic and Poland, inflation targeting policy was officially implemented in 1998. Although there is evidence of an intercept shift as found in Table 2, the parameters are found to be stable (see Table 4 where the F-tests are insignificant at the breakpoint $1998 \mathrm{~m} 12$ for both countries). There is the concern of definition of inflation targeting regimes in emerging markets (Amato and Gerlach, 2002). The criteria include a public announcement of a numerical target for inflation or a commitment to price stability, and they are not particularly helpful in defining the policy framework for emerging economies. Central banks in developing economies have tended to adopt relatively simple method initially as a way to signal their commitment to achieving better inflation control. Amato and Gerlach (2002) argue that the authorities' aspiration or ambition in containing inflation rather than as a hard target may be best described as the initial inflation targeting for the transition economies. This might explain the absence of structural changes in parameters. All in all, these test results are satisfactory for us to draw inference from the estimates.

See Table $3 \mathrm{a}$ and $3 \mathrm{~b}$. In terms of the predicted signs on the coefficients, positive signs are expected for inflation, GDP and exchange rates in the interest rate equation, whereas negative signs should be expected for them in the money equation, if policy makers wish to

\footnotetext{
14 Crespo-Cuaresma et al. (2005) also found that the time series on nominal exchange rates did not display a structural break during the currency crises in the Czech Republic and Slovakia in modelling exchange rates with interest rates and money as regressors.
} 
contain instability of these key variables. By looking at the statistically significant coefficients at the $5 \%$ level, we notice the correctly signed coefficients for all, except for the gex in Romania where a significant positive sign is found in the money equation.

Overall, an interesting finding is that more significant coefficients are found on the inflation deviation in the money equation rather than in the interest rate equation: the coefficients on ginfl are statistically significant at the 5\% level in all cases in $\Delta m$ equation except for Bulgaria, whilst three cases in $\Delta r$ equation. The evidence reveals that money tends to be more responsive to inflation rate gap. On the other hand, the sensitivity to the exchange rate gap appears to be stronger in interest rates, as more coefficients on gex are statistically significant in the $\Delta r$ model. These results imply that the authorities use interest rate changes in order to defend the value of their currencies ${ }^{15}$, whereas control of money plays a crucial role to contain inflation.

In respect of individual countries, this effect is particularly strong for the 'first wave' new EU member states of the Czech Republic, Poland, Slovakia and Slovenia. This can be explained, for example with the Czech Republic, where the monetary policy makers relied on credit refinancing quotas and other direct measures in targeting monetary growth, whereas nominal interest rates were set at high level even in the decline of inflation, mainly serving for an exchange rate peg, providing credibility to foreign investors. This eventually attracted large inflows of foreign capital in the 1990s. In this respect, the argument that change in interest rates have an effect on the inflation indirectly through their effect on the money supply, may have a limited application to transition economies. Slovakia's inflation targeting is only implicit with a considerable discretion, whereas Slovenia officially opted for a managed floating regime until joining the ERM II, and the exchange rate targeting seems to

\footnotetext{
15 This is consistent with the study of Crespo-Cuaresma et al. (2005) in their monetary approach to exchange rates in the Central Eastern European countries.
} 
be apparent in interest rate equations (see also Beblavy 2002 and Frömmel and Schobert 2006).

The size of the significant coefficients on gex in $\Delta r$ equation (Table 3a) is relatively high, though varying considerably amongst countries ranging from around 1 in Slovakia to the highest of 6 in Poland, suggesting that $1 \%$ increase in the exchange rate deviation leads to a rise of from $1 \%$ to $6 \%$ in interest rates. In emerging economies, government and firms tend to rely on foreign currency denominated debt, hence the exchange rate changes can have a significant impact on debtors' balance sheets or the profitability of banks (Amato and Gerlach 2002). Judging from this, our result implies that the central banks appear to choose a relatively stable nominal exchange rate to safeguard the value of currency. Note that Poland abandoned the zloty's peg in October of 1991, replaced by a crawling peg with a preannounced devaluation of $1.8 \%$ per month against a basket of currencies ${ }^{16}$. During the 1995 , the band was widened to $\pm 7 \%$ followed by an independent floating system in 2000 . This may explain the high responsiveness of interest rates against an exchange rate movement.

For Hungary and Romania, based on the statistical significance at the 5\% level, both interest rates and money seemed to have played a role in adjusting the inflation rate. Note that Hungary entered the transition period with a high rate of inflation, e.g. $15 \%$ in 1987 , and nearly 30\% in 1989 mainly due to a rapid liberalization of the Hungarian economy. Hungary adopted a fixed peg with adjustment bands to account for the inflation differential between Hungary and the countries in its basket, i.e. US\$ and ECU. The prime concern in the Hungarian economy is visible; high rates of inflation were contained by raising interest rates

\footnotetext{
16 The stabilisation of the economy in Poland started with a high rate of inflation and this reduced the price competitiveness of Polish exports with the zloty devalued by $16.8 \%$ in 1991 (Kutan and Brada 2000).
} 
accompanied with the contraction of money supply. In the case of Bulgaria, unlike the above 'first' new EU countries, Taylor rule appears to be supported in terms of targeting inflation, whereas the McCallum rule has been found more appropriate for protecting the exchange rates.

It is noted that all the coefficients on $g g d p$ are insignificant in the $\Delta r$ equation and only two coefficients are found to be significant in $\Delta m$ equation. It seems that policymakers are not too committed on the output fluctuation as an overriding issue in setting interest rates $^{17}$. In the study of Sánchez-Fung (2005) for Dominican Republic, he also finds that the central bank targets less of output gap, instead the exchange rate gap between the parallel and official is more of a concern.

\section{Impulse Response function (IRF)}

As a robustness test, we further investigate the alternative hypotheses by producing the IRF. The IRF captures the dynamic effects of a shock on endogenous variables. We analyse the four variables in the VAR framework in two-fold: one with $\Delta r$, ginfl, ggdp and gex, and the other with $\Delta m$, ginfl, ggdp and gex. The former implies the Taylor's rule, whereas the latter, the McCallum's rule. We focus on the impact of shock derived from inflation gap and exchange rate gap on money and interest rates $^{18}$. A shock originating in inflation $($ ginfl $)$ and

17 There is general consensus that inflation-targeting monetary authorities are generally not ambitious on output fluctuations among developed economies (Svensson 2002).

18 The technique of a vector autoregressive and the corresponding impulse response function has been often utilised in the study of monetary policy transmission, see recent study for the U.S. by Brissimis and Magginas (2006) and Hanson (2006). 
exchange rates (gex) not only affects their own variables, but it is also transmitted to interest rates $(\Delta r)$ and money $(\Delta m)$ through the VAR system.

Innovations, $u_{t}$ in the VAR system may be contemporaneously correlated and that may have common components. It is postulated that $u_{t}$ is a linear combination of the pure innovations, $\varepsilon_{t}$. In the matrix form,

$u_{t}=A \varepsilon_{t}$

The pure innovations are serially uncorrelated and orthogonal to each other. The pure innovations will have a contemporaneous effect on endogenous variables. In order to interpret the impulses, a transformation $\left(A^{-1}\right)$ is applied to the innovations so that they become uncorrelated, such that

$\varepsilon_{t}=A^{-1} \boldsymbol{u}_{t} \sim(0, \mathrm{D})$

where $\mathrm{D}$ is a diagonal covariance matrix. The inverse of the Cholesky factor of the residual covariance matrix is used to orthogonalize the impulses in our study. The results are presented in Figure 1a with the inflation shock and $1 \mathrm{~b}$ with the exchange rate shock. The order of VAR is based on Schwarz Information Criterion. Dummy variables are specified in line in the model in Table 3 provided they are statistically significant.

Each plot shows the dynamic response of $\Delta r$ and $\Delta m$ to one standard deviation innovations in ginfl and gex over forecast horizons of up to 10 months ${ }^{19}$. Confidence intervals are estimated by using the Monte Carlo integration with 1000 draws. If the $90 \%$ confidence interval contains zero, this indicates that the estimated response is statistically no different from zero at the $10 \%$ level of significance. Note that the expected response of $\Delta r$

1910 months are the plausible range as the IRF mostly converge to the long-run equilibrium level within that time horizon. 
is expected to be positive, whereas that of $\Delta m$ is negative resulting from a positive shock in ginfl and gex, if economic theory holds.

Starting with inflation shock in Figure 1a, shock in ginfl initially causes positive impacts on interest rates (the first column) in Hungary and Poland at the $10 \%$ significance level. A closer inspection of IRF indicates that within approximately 3 to 5 months the dynamic effects of the shock will cease, as IRF approaches zero. A discernable negative impact on $\Delta m$ (the second column) is observed for the Czech Republic, Hungary and Poland and to a lesser degree for Slovakia where the confidence interval marginally contains zero. There is a sign of role of money as a policy instrument for containing inflation fluctuations, which is consistent with the estimation result.

In terms of exchange rate shock in Figure $1 \mathrm{~b}$, this, too, is supportive to the estimation results. $\Delta r$ in the Czech Republic, Poland, Slovakia and Slovenia positively responded from a shock in the exchange rate gap.

\section{Concluding remarks}

In this paper, we investigated the monetary policy reaction function based on the Taylor's and McCallum's hypotheses. We find more of significant coefficients on inflation deviation in the money equation than in interest rate equation, whereas the exchange rate deviation is found to be significant in the interest rate equation. This is, in particular, evident in the Czech Republic, Poland, Slovakia and Slovenia. For these countries, the Taylor rule may be suitable to exchange rate targeting, whereas the McCallum rule may be applicable to inflation targeting in empirical analysis. Evidence also reveals that for Hungary and Romania, inflation targeting coexists with that of exchange rates taking account of both reactions of interest rates and money. 
In the literature much attention is given to the hypothesis of Taylor type rule for developed economies. Our empirical results raise the question of relying on this for developing economies. We took a first step for applying both Taylor rule and McCallum rule for transition economies in analysing monetary policy reaction functions. Further investigation of the dual hypotheses for other developing countries would be of use to policy makers. 
Appendix 1 Inflation targets

\begin{tabular}{|c|c|c|}
\hline Country & Inflation target & Target's horizon \\
\hline Australia & $2 \%$ to $3 \%$ (since 1993 ) & Medium term \\
\hline Brazil & $5.1 \%$ (for 2005 ) & 1 year \\
\hline Canada & $1 \%$ to $3 \%$ (since 1998 ) & Medium term \\
\hline Chile & $2 \%$ to $4 \%$ (since 2001$)$ & Medium term \\
\hline Colombia & $3.5 \%$ to $4.5 \%$ (for 2007 ) & Medium term \\
\hline Czech Republic & $2 \%$ to $4 \%$ (since 2005$)$ & 1 year \\
\hline Mexico & $2 \%$ to $4 \%$ (since 2004$)$ & Medium term \\
\hline Norway & $1.5 \%$ to $3.5 \%($ since 2001$)$ & Medium term \\
\hline Peru & $1.5 \%$ to $3.5 \%($ since 2002$)$ & Medium term \\
\hline Philippines & $4 \%$ to $5 \%$ (for 2006) & 1 year \\
\hline Poland & $1.5 \%$ to $3.5 \%($ since 2004$)$ & Medium term \\
\hline Sweden & $1 \%$ to $3 \%$ (since 1995 ) & Medium term \\
\hline United Kingdom & $2 \%($ since 2004$)$ & Medium term \\
\hline
\end{tabular}

Source: various sources 


\section{Appendix 2 Data}

Monthly data retrieved from IFS with the code and Datastream:

Discount rates 60ZF except for Romania where Repurchase Agreement 60A. ZA is used. For the Czech Republic, discount rates start from 1995m12Industrial production 66ZF is used for GDP. For Bulgaria the data are only available 2000m1 onward.

Exchange rates RF.ZF. NC/US\$ (where NC is national currency).

Consumer price index, CPI 64ZF. For Hungary monthly CPI starts $1995 \mathrm{ml}$ onward, which is retrieved from Datastream.

Real effective exchange rate RECZF

Money (currency and demand deposits) 34ZF. For Hungary (currency) and Slovenia (base money), money is retrieved from Datastream.

Note that we also tested two alternative variables for money aggregate:

i) the assets in the balance sheet of central banks, i.e. foreign assets 31N..ZF and domestic credit 32...ZF (Sánchez-Fung 2005) and

ii) monetary base, i.e. currency outside banking institutions $14 \mathrm{~A}$..ZF and reserves in the banking sector with central banks $20 \ldots \mathrm{ZF}$.

We did not purse these alternatives due to poor performance. 


\section{References}

Amato, J.D. and S. Gerlach. (2002). Inflation targeting in emerging market and transition economies: Lessons after a decade, European Economic Review, 46, 781-790.

Bai, J. (1996). Estimation of a change point in multiple regression model, Review of Economics and Statistics, 79, 551-563.

Banerjee, A., J. Dolado, J.W. Galbraith and D.F. Hendry (1993). Cointegration, Error-Correction and the Econometric Analysis of Non-Stationary Data: Advanced Texts in Econometrics, Oxford University Press.

Beblavy, M. (2002). Exchange rate and exchange rate regime in Slovakia: Recent developments, International Center for Economic Growth European Center Working Paper on Macroeconomi Studies, No. 5, Budapest.

Brissimis, S.N. and N.S.Magginas (2006). Forward-looking information in VAR models and the price puzzle, Journal of Monetary Economics, 53, 1225-1234.

Calvo, G.A. and C.M. Reinhart (2002). Fear of floating, Quarterly Journal of Economics, 117, 379-408.

Clarida, R., J. Gali and M. Gertler (1998). Monetary policy rules in practice: some international evidence, European Economic review, 42, 1033-1067.

Crespo-Cuaresma, J., J. Fidrmuc, and R. Macdonald (2005). The monetary approach to exchange rates in the CEECs, Economics of Transition, 13(2), 395-416.

Frömmel, M. and F. Schobert (2006). Monetary policy rules in Central and Eastern Europe, Leibniz Universität Hannover, Discussion Paper No. 341.

Ghatak, S. And J.R.Sanchez-Fung (2007), Monetary economics in developing countries,_Palgrave, Macmillan.

Ghatak,S and W. Spanjers (2007), Monetary Policy Rules, Transition Economies and The Impact of Ambiguity, International Journal of Development Issues, 6(1), 26 - 37. 
Greenspan, A. (2004). Risk and uncertainty in monetary policy. American Economic Review 94 (2), 33-40.

Hanson, M.S. (2006). Varying monetary policy regimes: A vector autoregressive investigation. Journal of Economics and Business, 58, 407427.

Hodrick, R.J. and E.C. Prescott (1997). Postwar U.S. business cycles: an empirical investigation', Journal of Money, Credit and Banking, 29, 1-16.

Kutan, Ali, M. and J.C. Brada (2000) The evolution of monetary policy in transition economies, March/April, 2000, Federal Reserve Bank of St. Louis, 31-40.

MacKinnon, J.G. (1991). Critical values for cointegration tests, in R.F. Engle and C.W.J. Granger (eds.), Long-run economic relationships: Readings in cointegration, Chapter 13, Oxford University Press.

McCallum, B. T. (1987). The case for rules in the conduct of monetary policy: a concrete example, Weltwirtschaftliches Archives, 123(3), 415429.

McCallum, B. T. (1988). Robustness properties of a rule for monetary policy, Carnegie-Rochester Conference Series on Public Policy, 29, 5384.

Moore, T., C.J. Green and V. Murinde (2006). Financial Sector Reforms and Stochastic Policy Simulation: a Flow of Funds Model for India, the Journal of Policy Modelling, 28(3), 319-333.

Phillips, P.C.B. (1987). Time Series Regression with a Unit Root, Econometrica, 55, 277-301.

Sánchez-Fung, José R. (2005). Estimating a monetary policy reaction function for the Dominican republic, International Economic Journal, 19, 563-577.

Savvides, A. (1998). Inflation and monetary policy in selected West and Central African countries, World Development, 26, 809-827. 
Schmidt-Hebbel, K. and Tapia M. (2002). Inflation targeting in Chile, North American Journal of Economics and Finance, 13, $125-146$.

Shortland, A. And D. Stasavage (2004). What determines monetary policy in the Franc zone? Estimating a reaction function for the BCEAO, Journal of African Economies, 13(4), 518-535.

Svensson, L.E.O. (2002). Inflation targeting: Should it be modelled as an instrument rule or a targeting rule? European Economic Review, 46, 771-780.

Svensson, L. E. O. (2003). What is wrong with Taylor rules? Using judgment in monetary policy through targeting rules. Journal of Economic Literature, 41 (2), 426-477.

Taylor, J.B. (1979). Staggered wage setting in a macro model, American Economic Review, Papers and Proceedings, 69, 108-113.

Taylor, J.B. (1993). Discretion versus policy rules in practice, Carnegie Rochester Conference Series on Public Policy, 39, $195-214$.

Taylor, J.B. (1999). Monetary policy rules, The University of Chicago Press, Chicago.

Taylor,J.B. (2007), The Explanatory Power of Monetary Policy Rules ,The Adam Smith Lecture,Annual Meeting of the

National Association of Business Economics, September 10, 2007, San Francisco

Woodford, M. (2004). Inflation targeting and optimal monetary policy, Federal Reserve Bank of St. Louis Review, 86, 15-41. 


\section{Appendix 3 Descriptive statistics}

\begin{tabular}{|c|c|c|c|c|c|c|c|c|c|c|}
\hline & \multicolumn{5}{|c|}{ Czech Rep. } & \multicolumn{5}{|l|}{ Hungary } \\
\hline & $r$ & ginfl & $g g d p$ & gex & $m$ & $r$ & ginfl & $g g d p$ & gex & $m$ \\
\hline Mean & 6.2887 & 0.0068 & 0.0002 & -0.0001 & 6.4474 & 15.2228 & 0.0000 & 0.0000 & 0.0000 & 7.6876 \\
\hline Median & 5.0000 & -0.1305 & 0.0001 & -0.0012 & 6.2991 & 12.3750 & -0.0857 & -0.0012 & 0.0017 & 7.7668 \\
\hline Maximum & 18.2000 & 3.4033 & 0.0743 & 0.1097 & 7.1968 & 28.0000 & 4.2177 & 0.0746 & 0.1091 & 8.6713 \\
\hline inimum & 1.7500 & -0.9539 & -0.0726 & -0.1379 & 5.9087 & 6.0000 & -0.8952 & -0.0533 & -0.1110 & 6.7301 \\
\hline Std. Dev. & 4.6414 & 0.6176 & 0.0271 & 0.0513 & 0.4343 & 7.1899 & 0.5468 & 0.0242 & 0.0398 & 0.5999 \\
\hline kewness & 0.8178 & 2.5482 & 0.2061 & -0.1298 & 0.2799 & 0.4386 & 3.4783 & 0.4892 & -0.0040 & -0.1591 \\
\hline \multirow[t]{3}{*}{ Kurtosis } & 2.1900 & 12.2411 & 3.5195 & 2.8162 & 1.4610 & 1.7893 & 25.2846 & 3.4115 & 3.1227 & 1.7161 \\
\hline & \multicolumn{5}{|l|}{ Poland } & \multicolumn{5}{|l|}{ Slovakia } \\
\hline & $r$ & ginfl & $g g d p$ & gex & $m$ & $r$ & ginfl & $g g d p$ & gex & $m$ \\
\hline Mean & 16.1774 & -0.0008 & -0.0001 & -0.0001 & 11.4670 & 7.7881 & 0.0000 & 0.0000 & 0.0000 & 12.2161 \\
\hline Median & 19.0000 & -0.0284 & 0.0019 & 0.0038 & 11.5450 & 8.8000 & -0.2356 & 0.0024 & 0.0001 & 12.0122 \\
\hline Maximum & 31.0000 & 2.4282 & 0.0872 & 0.0978 & 12.5275 & 12.0000 & 4.8835 & 0.0689 & 0.0988 & 13.1787 \\
\hline Minimum & 4.0000 & -2.6574 & -0.0823 & -0.1417 & 10.1331 & 3.0000 & -1.0328 & -0.0657 & -0.1016 & 11.5190 \\
\hline Std. Dev. & 8.5708 & 0.6420 & 0.0309 & 0.0390 & 0.6095 & 2.4934 & 0.8475 & 0.0255 & 0.0421 & 0.4693 \\
\hline Skewness & -0.1134 & 0.3994 & 0.0344 & -0.4797 & -0.4212 & -0.3755 & 3.4794 & 0.0820 & -0.1054 & 0.6763 \\
\hline Kurtosis & 1.5672 & 6.9225 & 3.0731 & 4.2001 & 2.3782 & 2.4970 & 17.9048 & 3.0336 & 2.4418 & 2.1394 \\
\hline
\end{tabular}


Appendix 3 Descriptive statistics (continued)

\begin{tabular}{|c|c|c|c|c|c|c|c|c|c|c|}
\hline & \multicolumn{5}{|l|}{ Slovenia } & \multicolumn{5}{|l|}{ Bulgaria } \\
\hline & $r$ & ginfl & $g g d p$ & gex & $m$ & $r$ & ginfl & $g g d p$ & gex & $m$ \\
\hline Mean & 9.9412 & 0.0035 & -0.0004 & 0.0002 & 6.6026 & 3.1840 & 0.1932 & 0.0000 & -0.0092 & 8.9047 \\
\hline Median & 11.0000 & 0.0190 & -0.0002 & 0.0017 & 6.7117 & 2.9450 & 0.2495 & -0.0057 & -0.0071 & 8.8495 \\
\hline Maximum & 17.0000 & 1.0362 & 0.0642 & 0.0969 & 7.2262 & 4.7900 & 2.9285 & 0.2005 & 0.0764 & 9.6852 \\
\hline Minimum & 4.5000 & -1.2690 & -0.0811 & -0.1185 & 5.3706 & 1.8900 & -2.4811 & -0.1293 & -0.1317 & 8.2368 \\
\hline Std. Dev. & 3.3202 & 0.4714 & 0.0237 & 0.0515 & 0.4865 & 0.9177 & 1.0720 & 0.0633 & 0.0455 & 0.4010 \\
\hline Skewness & 0.2702 & -0.0759 & -0.3726 & -0.2232 & -0.6765 & 0.3506 & -0.1383 & 0.4596 & -0.2757 & 0.2174 \\
\hline \multirow[t]{3}{*}{ Kurtosis } & 3.1000 & 2.8414 & 3.7335 & 2.3372 & 2.4368 & 1.7059 & 3.6040 & 3.4016 & 2.6195 & 1.8937 \\
\hline & \multicolumn{5}{|l|}{ Romania } & & & & & \\
\hline & $r$ & ginfl & $g g d p$ & gex & $m$ & & & & & \\
\hline Mean & 32.1155 & 0.0000 & 0.0000 & 0.0000 & 1.1521 & & & & & \\
\hline Median & 35.0000 & -0.2183 & 0.0065 & 0.0034 & 1.1942 & & & & & \\
\hline Maximum & 70.0000 & 25.3569 & 0.1820 & 0.3543 & 3.5659 & & & & & \\
\hline Minimum & 7.5000 & -4.5789 & -0.1651 & -0.2106 & -1.6145 & & & & & \\
\hline Std. Dev. & 15.4268 & 2.8153 & 0.0595 & 0.0906 & 1.3662 & & & & & \\
\hline Skewness & 0.4524 & 5.5447 & 0.0296 & 0.7493 & -0.1182 & & & & & \\
\hline Kurtosis & 3.2809 & 46.9384 & 3.2446 & 5.7242 & 2.0045 & & & & & \\
\hline
\end{tabular}


Table 1 Unit root test: Augmented Dickey-Fuller (ADF) and Phillips Perons (PP) tests

\begin{tabular}{|c|c|c|c|c|c|c|c|c|}
\hline & Level & Differenced & Level & Differenced & Level & Differenced & Level & Differenced \\
\hline ADF & Czech Rep. & & Hungary & & Poland & & Slovakia & \\
\hline$r$ & $-0.966(0)$ & $-13.667(0)$ & $-0.487(0)$ & $-10.868(0)$ & $-0.678(0)$ & $-11.550(0)$ & $-1.179(0)$ & $-11.974(0)$ \\
\hline ginfl & $-3.757(5)$ & & $-2.651(12)$ & $-9.758(12)$ & $-4.327(12)$ & & $-11.089(0)$ & \\
\hline$g g d p$ & $-4.511(1)$ & & $-3.526(1)$ & & $-3.495(3)$ & & $-4.301(3)$ & \\
\hline gex & $-4.348(1)$ & & $-4.141(1)$ & & $-5.144(1)$ & & $-4.266(1)$ & \\
\hline$m$ & $-0.525(0)$ & $-14.082(0)$ & $-1.081(13)$ & $-2.409(12)$ & $-2.126(1)$ & $-17.179(0)$ & $-0.503(0)$ & $-14.134(0)$ \\
\hline ADF & Slovenia & & Bulgaria & & Romania & & & \\
\hline$r$ & $-1.527(0)$ & $-12.161(0)$ & $-2.724(0)$ & $-13.012(0)$ & $-2.020(0)$ & $-10.285(0)$ & & \\
\hline ginfl & $-11.11(0)$ & & $-10.477(0)$ & & $-6.544(0)$ & & & \\
\hline ggdp & $-6.747(0)$ & & $-1.484(11)$ & $-3.869(11)$ & $-2.636(12)$ & $-3.963(11)$ & & \\
\hline gex & $-4.121(1)$ & & $-2.417(0)$ & $-11.000(0)$ & $-4.774(3)$ & & & \\
\hline$m$ & $-3.812(1)$ & $-25.302(0)$ & $-2.801(1)$ & $-8.880(0)$ & $-0.202(12)$ & $-3.901(11)$ & & \\
\hline & Level & Differenced & Level & Differenced & Level & Differenced & Level & Differenced \\
\hline PP & Czech Rep. & & Hungary & & Poland & & Slovakia & \\
\hline$r$ & $-0.974(6)$ & $-13.453(6)$ & $-0.659(6)$ & $-11.125(5)$ & $-0.811(7)$ & $-11.902(7)$ & $-1.201(6)$ & $-12.101(6)$ \\
\hline ginfl & $-12.820(21)$ & & $-10.856(5)$ & & $-9.571(4)$ & & $-11.579(11)$ & \\
\hline$g g d p$ & $-7.008(6)$ & & $-6.173(7)$ & & $-10.042(7)$ & & $-7.798(5)$ & \\
\hline gex & $-3.774(3)$ & & $-3.595(3)$ & & $-4.179(6)$ & & $-3.616(3)$ & \\
\hline$m$ & $-0.731(4)$ & $-14.1257(4)$ & $-0.087(8)$ & $-17.7826(6)$ & $-2.081(14)$ & $-17.668(2)$ & $-0.767(3)$ & $-14.158(1)$ \\
\hline $\mathbf{P P}$ & Slovenia & & Bulgaria & & Romania & & & \\
\hline$r$ & $-1.534(2)$ & $-12.161(1)$ & $-2.786(5)$ & $-13.100(3)$ & $-1.960(6)$ & $-10.569(5)$ & & \\
\hline ginfl & $-11.114(1)$ & & $-10.463(3)$ & & $-6.114(9)$ & & & \\
\hline
\end{tabular}




\begin{tabular}{|l|r|r|r|r|r|r|}
\hline ggdp & $-6.728(3)$ & & $-7.933(4)$ & & $-7.371(5)$ & $-3.173(10)$ \\
\hline gex & $-3.400(3)$ & & $-3.030(10)$ & & $-1.596(9)$ & $-20.618(8)$ \\
\hline$m$ & $-3.228(1)$ & $-25.504(1)$ & $-2.492(6)$ & $-9.245(5)$ & & \\
\hline
\end{tabular}

Critical values: 3.473 for $1 \%$ level, 2.88 for $5 \%$ level and 2.577 for $10 \%$ level with a sample period from around $1994 \mathrm{~m} 1$ to $2006 \mathrm{~m} 12$, except for ggdp in Bulgaria, which is 3.511 for $1 \%$ level, 2.897 for 5\% level and 2.586 for $10 \%$ level with a sample period 2000m1 to 2006m12 (MacKinnon 1991). Lag length criterion is based on Shwarz Information Criterion for ADF tests, starting from a maximum lag of 13. Bertlett Kernel estimation method is utilised with the lag length criterion of Newey-West Bandwidth for the PP tests. 
Table 2 Structural break tests

\begin{tabular}{|c|c|c|c|c|c|c|}
\hline & $\begin{array}{l}\text { Czech } \\
\text { Rep. }\end{array}$ & Hungary & Poland & Slovakia & Slovenia & Romania \\
\hline \multicolumn{7}{|c|}{$\begin{array}{l}\Delta \mathbf{r} \\
\text { equation }\end{array}$} \\
\hline D1 & 1.543 & 1.219 & 0.019 & 1.316 & 0.120 & 0.072 \\
\hline D2 & $7.028^{*}$ & 0.874 & 0.185 & 0.692 & 0.340 & 2.182 \\
\hline D3 & $14.661^{*}$ & & & & & \\
\hline D4 & & & & & & 1.613 \\
\hline D5 & & & 0.091 & & & \\
\hline D6 & & 0.965 & & & & \\
\hline D7 & & & 0.788 & & & \\
\hline D8 & & & & 0.002 & & \\
\hline D9 & 0.078 & 0.132 & 2.212 & 0.971 & 0.018 & \\
\hline \multicolumn{7}{|c|}{$\begin{array}{l}\Delta \mathrm{m} \\
\text { equation }\end{array}$} \\
\hline D1 & $5.655^{*}$ & $12.877^{*}$ & 0.062 & 1.289 & 0.203 & 0.648 \\
\hline D2 & 0.192 & 2.710 & $14.264 *$ & 0.020 & $8.498 *$ & 7.977* \\
\hline D3 & 1.572 & & & & & \\
\hline D4 & & & & & & 9.017* \\
\hline D5 & & & $10.078 *$ & & & \\
\hline D6 & & 1.124 & & & & \\
\hline D7 & & & 3.494 & & & \\
\hline D8 & & & & 1.313 & & \\
\hline D9 & 0.0009 & 0.102 & 0.110 & 0.030 & $4.395^{*}$ & \\
\hline
\end{tabular}

Notes:

\begin{tabular}{|l|l|}
\hline D1 & $\begin{array}{l}\text { Asia and Russia financial crises, floating regime in Czech Rep.: period dummy 1 } \\
\text { during 1997m5 to 1998m8, 0 otherwise }\end{array}$ \\
\hline D2 & $\begin{array}{l}\text { Asia and Russia financial crises: shift dummy, 1 for 1997m5 onward, 0 } \\
\text { otherwise }\end{array}$ \\
\hline D3 & $\begin{array}{l}\text { Inflation targeting in the Czech Rep.: 1 for 1998m1 onward, 0 otherwise } \\
\text { Massive devaluation followed by undeclared policy change in 1998 with respect } \\
\text { to exchange rates and high inflation in Romania: } \\
1 \text { for 1997m1 onward, 0 otherwise }\end{array}$ \\
\hline D4 & $\begin{array}{l}\text { Inflation targeting in Poland: 1 for 1998m9 onward, 0 otherwise } \\
\text { onward, 0 otherwise }\end{array}$ \\
\hline D6 & Floating regime in Poland: 1 for 2000m4 onward, 0 otherwise \\
\hline D7 & Floating regime in Slovakia: 1 for 1998m10 onward, 0 otherwise \\
\hline D8 & $\begin{array}{l}\text { Entry to the EU for Czech Rep. Hungary, Poland, Slovakia and Slovenia: } 1 \text { for } \\
\text { 2004m5 onward, 0 otherwise }\end{array}$ \\
\hline D9
\end{tabular}

Likelihood ratio test chi-squared $(\mathrm{df}=1)$ with a critical value of 3.84 at the $5 \%$ level. * significant at the $5 \%$ level. Bulgaria is not applicable, since the sample period starts from $2000 \mathrm{~m} 1$. 
Table 3a Monetary policy reaction model: dependent variable $\Delta r$

\begin{tabular}{|c|c|c|c|c|c|c|c|c|c|c|c|c|c|c|}
\hline & \multicolumn{2}{|c|}{ Czech Rep. } & \multicolumn{2}{|c|}{ Hungary } & \multicolumn{2}{|c|}{ Poland } & \multicolumn{2}{|c|}{ Slovakia } & \multicolumn{2}{|c|}{ Slovenia } & \multicolumn{2}{|c|}{ Bulgaria } & \multicolumn{2}{|c|}{ Romania } \\
\hline & Coef. & t-ratio & Coef. & t-ratio & Coef. & t-ratio & Coef. & t-ratio & Coef. & t-ratio & Coef. & t-ratio & Coef. & t-ratio \\
\hline$\alpha$ & -0.084 & -1.481 & -0.122 & -0.751 & -0.091 & -0.446 & 0.009 & 0.125 & 0.035 & 0.232 & -0.119 & -0.779 & -0.004 & -0.008 \\
\hline$\Delta r(-1)$ & $-0.217^{*}$ & -2.380 & 0.070 & 0.905 & 0.014 & 0.161 & 0.005 & 0.056 & -0.047 & -0.556 & $-0.325^{*}$ & -3.046 & 0.092 & 1.065 \\
\hline ginfl & -0.060 & -0.601 & $0.260 *$ & 2.201 & -0.010 & -0.073 & 0.034 & 1.121 & 0.164 & 1.491 & $0.109 *$ & 2.792 & $0.167 *$ & 2.430 \\
\hline$g g d p$ & 1.393 & 0.572 & 1.341 & 0.640 & 0.720 & 0.312 & -0.829 & -1.011 & 1.090 & 0.548 & 0.196 & 0.206 & 4.670 & 1.354 \\
\hline gex & $3.025^{*}$ & 2.342 & 0.979 & 0.761 & $6.332 *$ & 3.521 & $1.030 *$ & 2.035 & $2.511 *$ & 2.652 & -0.112 & -0.141 & -0.940 & -0.485 \\
\hline dummy & & & $2.828 *$ & 3.443 & & & & & & & & & & \\
\hline $\mathrm{R}^{2}$ & 0.101 & & 0.303 & & 0.210 & & 0.110 & & 0.136 & & 0.346 & & 0.189 & \\
\hline Breusch-Godfrey & 0.115 & & 2.838 & & 0.534 & & 1.474 & & 2.051 & & 0.039 & & 1.755 & \\
\hline Breusch-Pagan & 22.281 & & 18.139 & & 10.336 & & 16.287 & & 28.137 & & 16.652 & & 22.964 & \\
\hline Ramsey RESET & 0.962 & & 1.916 & & 0.915 & & 0.079 & & 2.051 & & 0.656 & & 3.617 & \\
\hline
\end{tabular}

\section{Table 3b Monetary policy reaction model: dependent variable $\mathbf{A m}$}

\begin{tabular}{|c|c|c|c|c|c|c|c|c|c|c|c|c|c|c|}
\hline & \multicolumn{2}{|c|}{ Czech Rep. } & \multicolumn{2}{|c|}{ Hungary } & \multicolumn{2}{|c|}{ Poland } & \multicolumn{2}{|c|}{ Slovakia } & \multicolumn{2}{|c|}{ Slovenia } & \multicolumn{2}{|c|}{ Bulgaria } & \multicolumn{2}{|c|}{ Romania } \\
\hline & Coef. & t-ratio & Coef. & t-ratio & Coef. & t-ratio & Coef. & & Coef. & t-ratio & Coef. & t-ratio & Coef. & t-ratio \\
\hline$\alpha$ & $0.009 *$ & 3.532 & $0.063^{*}$ & 8.960 & $0.035^{*}$ & 4.957 & $0.016 *$ & 2.137 & $0.035 *$ & 3.515 & $0.137 *$ & 5.233 & $0.188^{*}$ & 12.993 \\
\hline$\Delta m(-1)$ & $-0.183^{*}$ & -2.535 & $-0.361 *$ & -4.456 & $-0.275^{*}$ & -3.447 & -0.100 & -1.236 & $-0.658 *$ & -10.011 & -0.244 & -1.598 & $-0.314^{*}$ & -3.191 \\
\hline ginfl & $-0.017 *$ & -2.959 & $-0.012 *$ & -2.479 & $-0.021 *$ & -4.030 & $-0.014 *$ & -3.207 & $-0.022 *$ & -2.047 & -0.003 & -0.664 & $-0.005^{*}$ & -3.111 \\
\hline$g g d p$ & -0.044 & -0.353 & $-0.173^{*}$ & -2.049 & -0.004 & -0.044 & -0.135 & -1.008 & -0.158 & -0.829 & $-0.411^{*}$ & -2.520 & 0.049 & 0.700 \\
\hline gex & 0.046 & 0.775 & 0.066 & 1.101 & 0.011 & 0.119 & -0.029 & -0.313 & 0.155 & 1.333 & $-0.414^{*}$ & -2.791 & $0.107 *$ & 2.704 \\
\hline dummy & $0.357 *$ & 1.986 & & & $-0.018 *$ & -3.140 & & & $-0.026^{*}$ & -2.600 & & & $-0.020 *$ & -2.975 \\
\hline $\mathrm{R}^{2}$ & 0.299 & & 0.679 & & 0.314 & & 0.181 & & 0.481 & & 0.293 & & 0.807 & \\
\hline Breusch-Godfrey & 0.566 & & 24.500 & & 0.591 & & 1.543 & & 3.281 & & 0.373 & & 0.067 & \\
\hline Breusch-Pagan & 24.149 & & 13.940 & & 20.317 & & 13.629 & & 13.304 & & 11.389 & & 28.114 & \\
\hline Ramsey RESET & 1.026 & & 5.217 & & 1.005 & & 0.131 & & 2.579 & & 3.051 & & 2.812 & \\
\hline
\end{tabular}

(See notes in the next page.) 


\section{Notes for Table 3}

* Significant at the $5 \%$ level.

Instrument variable method: IV used are lagged once and twice dependent and independent variables. Sample period $1994 \mathrm{~m} 1$ to $2006 \mathrm{~m} 12$ for Poland, Slovakia, Slovenia and Romaine, $1995 \mathrm{~m} 12$ to $2006 \mathrm{~m} 12$ for the Czech Republic, $1995 \mathrm{~m} 1$ to $2006 \mathrm{~m} 12$ for Hungary and $2000 \mathrm{~m} 1$ to

2006m12 for Bulgaria. Dummy: a pulse dummy 1995m2 for Hungary in $\Delta \mathrm{i}$ equation, a pulse dummy $2002 \mathrm{~m} 1$ for the Czech Republic and D2 for Poland and Slovenia and Romania in $\Delta \mathrm{m}$ equation.

Breusch-Godfrey serial correlation test: chi-square $(\mathrm{df}=2)$ with a critical value of 5.99 at the $5 \%$ level and 9.21 at the $1 \%$ level. Breusch-PaganGodfrey hetroskedasticity test: chi-squre ( $\mathrm{df}=16$, number of regressors including monthly dummies) with a critical value of 26.3 at the $5 \%$ level and 32.0 at the $1 \%$ level. Ramsey RESET stability test: F test with a critical value of 3.84 at the 5\% level and 6.63 at the $1 \%$ level, for Bulgaria with a critical value of 4.04 at the 5\% level and 7.11 at the $1 \%$ level. 
Table 4 Breakpoint tests: F test [Prob.]

\begin{tabular}{|l|c|c|c|c|c|}
\hline $\mathbf{\Delta r}$ & $\mathbf{1 9 9 6 m 1 2} * *$ & $\mathbf{1 9 9 8 m 1 2}$ & $\mathbf{2 0 0 0 m 1 2}$ & $\mathbf{2 0 0 2} \mathbf{m 1 2}$ & $\mathbf{2 0 0 4 m 1 2}$ \\
\hline Czech & $14.630[0.009]^{*}$ & $0.076[0.999]$ & $0.055[0.999]$ & $0.070[0.999]$ & $0.069[0.999]$ \\
\hline Hungary & $0.703[0.853]$ & $0.986[0.536]$ & $1.066[0.399]$ & $1.829[0.007]^{*}$ & $0.408[0.994]$ \\
\hline Poland & $0.503[0.981]$ & $0.729[0.894]$ & $0.563[0.991]$ & $0.275[0.999]$ & $0.325[0.999]$ \\
\hline Slovakia & $0.593[0.942]$ & $1.065[0.422]$ & $1.890[0.005]^{*}$ & $0.824[0.768]$ & $1.174[0.279]$ \\
\hline Slovenia & $0.258[0.999]$ & $0.416[0.999]$ & $0.362[0.999]$ & $0.278[0.999]$ & $0.219[0.999]$ \\
\hline Bulgaria & $\mathrm{NA}$ & $\mathrm{NA}$ & $\mathrm{NA}$ & $1.213[0.341]$ & $0.592[0.917]$ \\
\hline Romania & $0.717[0.845]$ & $0.177[0.999]$ & $0.202[0.999]$ & $0.243[0.999]$ & $0.365[0.998]$ \\
\hline $\boldsymbol{\Delta m}$ & $\mathbf{1 9 9 6 m 1 2 * *}$ & $\mathbf{1 9 9 8 m 1 2}$ & $\mathbf{2 0 0 0 m 1 2}$ & $\mathbf{2 0 0 2} \mathbf{m 1 2}$ & $\mathbf{2 0 0 4 m 1 2}$ \\
\hline Czech & $1.227[0.275]$ & $0.900[0.676]$ & $1.398[0.076]$ & $0.262[0.999]$ & $0.405[0.995]$ \\
\hline Hungary & $0.637[0.908]$ & $0.475[0.998]$ & $0.730[0.903]$ & $0.940[0.587]$ & $1.204[0.252]$ \\
\hline Poland & $0.324[0.999]$ & $0.510[0.996]$ & $0.605[0.981]$ & $0.666[0.939]$ & $0.539[0.962]$ \\
\hline Slovakia & $1.564[0.138]$ & $1.085[0.392]$ & $1.561[0.034]^{*}$ & $2.508[0.000]^{*}$ & $0.285[0.999]$ \\
\hline Slovenia & $6.207[0.000]^{*}$ & $9.055[0.000]^{*}$ & $5.411[0.000]^{*}$ & $1.450[0.067]$ & $1.459[0.103]$ \\
\hline Bulgaria & $\mathrm{NA}$ & $\mathrm{NA}$ & $\mathrm{NA}$ & $0.239[0.999]$ & $0.483[0.972]$ \\
\hline Romania & $1.736[0.073]$ & $1.325[0.162]$ & $1.062[0.406]$ & $1.127[0.309]$ & $1.471[0.112]$ \\
\hline
\end{tabular}

\section{Notes:}

$\mathrm{F}$ is the Chow test for parameter stability across the break date. We used the forecast version of the Chow test which requires estimation over one sub-sample only. We estimated over the first sub-sample for all 5 tests. Significance levels are based on

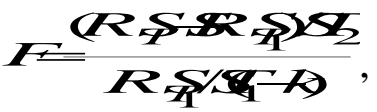
where $R S S_{T}$ is the residual sum of squares for the whole sample, $R S S_{T_{1}}$ is the residual sum of squares for the first $T_{1}$ observations. Prob is the probability of finding a value in excess of F.

\section{* $\quad$ significant at the $5 \%$ level.}

**For Poland, Slovenia and Romania, the breakpoint is $1997 \mathrm{m6}$, due to near singular matrix with a presence of $\mathrm{d} 2$ in the model.

Recall that Bulgaria start from 2000 due to data availability.

Separate slope coefficients across these breaks for Slovenia are shown in this table:

\begin{tabular}{|c|c|c|c|c|c|c|}
\hline $\begin{array}{l}\text { from } \\
1994 \mathrm{~m} 1\end{array}$ & to $1997 \mathrm{~m} 5$ & $\begin{array}{l}\text { to } \\
1998 \mathrm{~m} 11\end{array}$ & $\begin{array}{l}\text { to } \\
2000 \mathrm{~m} 11\end{array}$ & $\begin{array}{l}\text { to } \\
2002 \mathrm{~m} 11\end{array}$ & $\begin{array}{l}\text { to } \\
2004 \mathrm{~m} 11\end{array}$ & $\begin{array}{l}\text { Whole } \\
\text { (from table } \\
\text { 3b) }\end{array}$ \\
\hline ginfl & -0.015 & -0.016 & -0.006 & -0.024 & -0.031 & -0.020 \\
\hline$g g d p$ & 0.223 & 0.202 & 0.000 & -0.166 & -0.109 & -0.158 \\
\hline gex & 0.155 & 0.150 & 0.063 & 0.116 & 0.136 & 0.155 \\
\hline
\end{tabular}

For example, during the sample period from $1994 \mathrm{ml}$ to $1997 \mathrm{~m} 5$ the coefficient of ginfl is -0.015 . 
Figure 1a Response to Cholesky one SD innovation in inflation gap (ginfl)

Response of $\Delta \mathrm{r}$ : Czech Republic

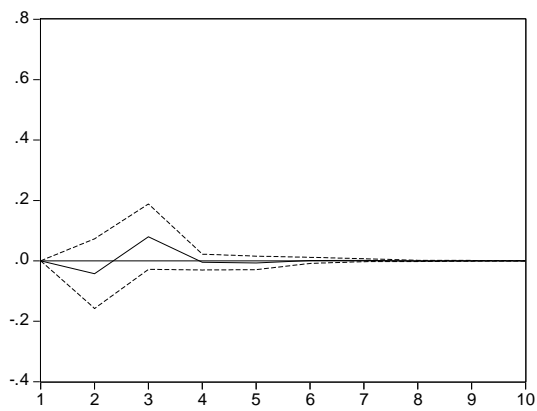

Response of $\Delta r$ : Hungary

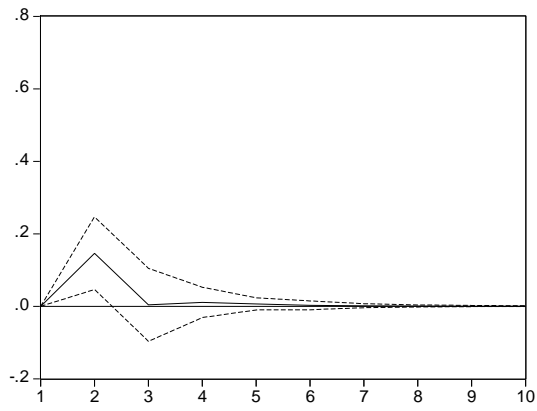

Response of $\Delta \mathrm{r}$ : Poland

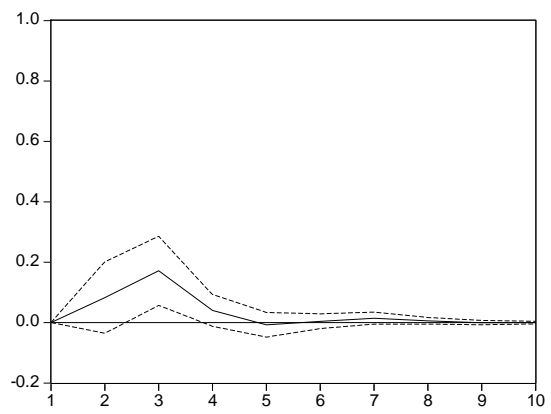

Response of $\Delta \mathrm{r}$ : Slovakia

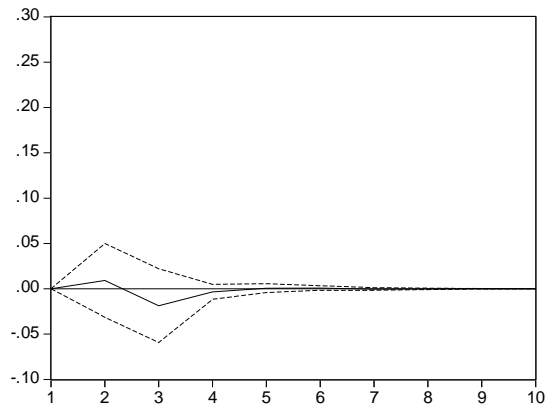

Response of $\Delta \mathrm{m}$ : Czech Republic

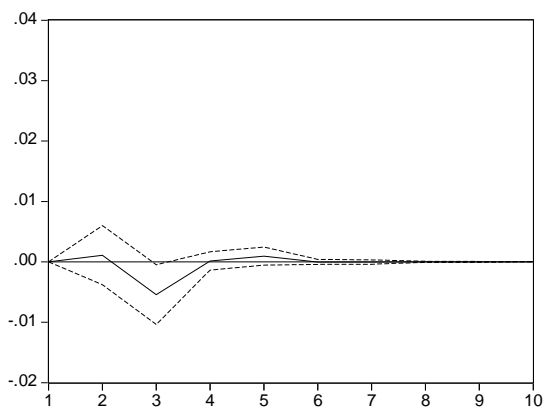

Response of $\Delta \mathrm{m}$ : Hungary

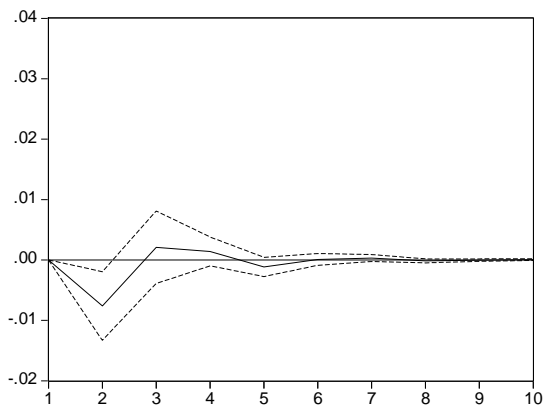

Response of $\Delta \mathrm{m}$ : Poland

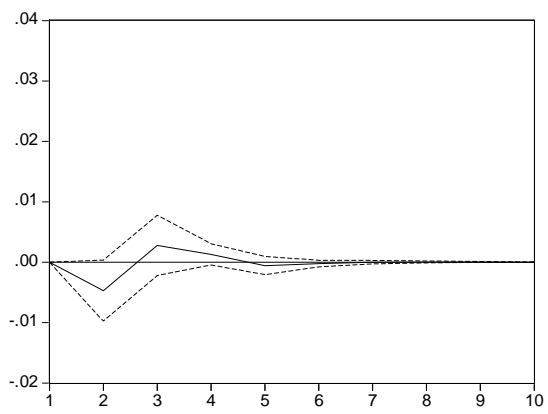

Response of $\Delta \mathrm{m}$ : Slovakia

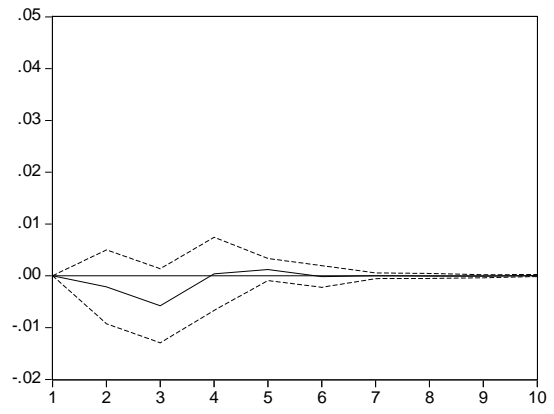


Figure 1a Response to Cholesky one SD innovation in inflation gap (ginfl) (to be continued)

Response of $\Delta \mathrm{r}:$ Slovenia

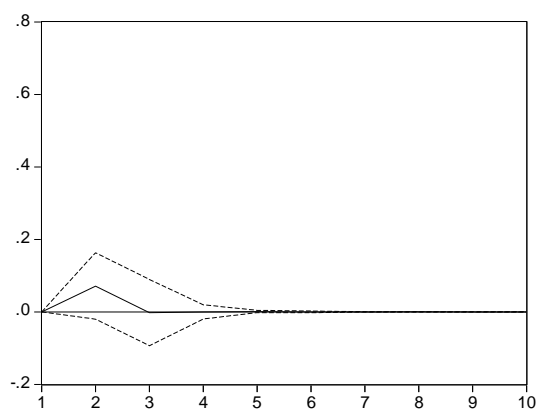

Response of $\Delta \mathrm{r}$ : Bulgraria

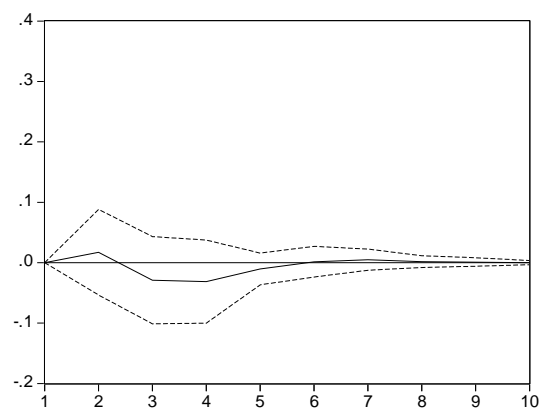

Response of $\Delta \mathrm{r}$ : Romania

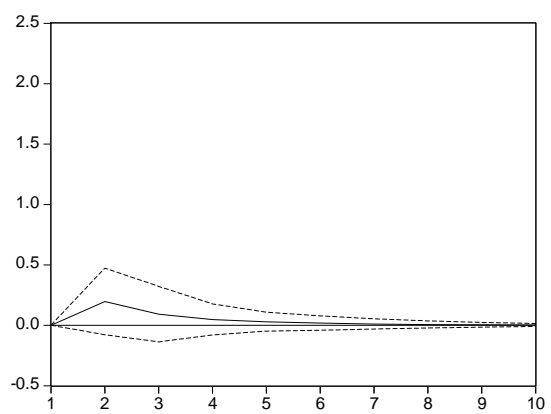

Response of $\Delta \mathrm{m}$ : Slovenia

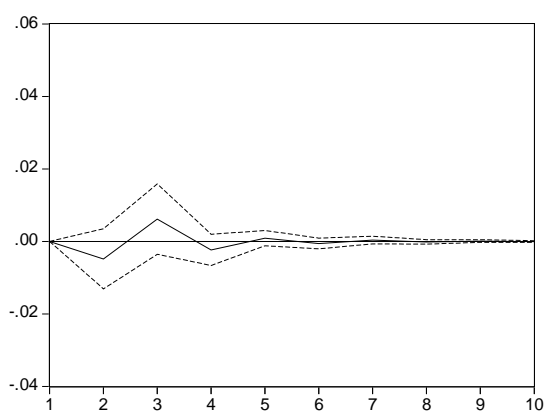

Response of $\Delta \mathrm{m}$ : Bulgaria

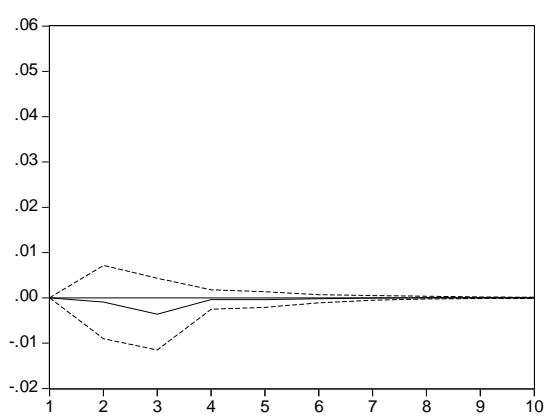

Response of $\Delta \mathrm{m}$ : Romania

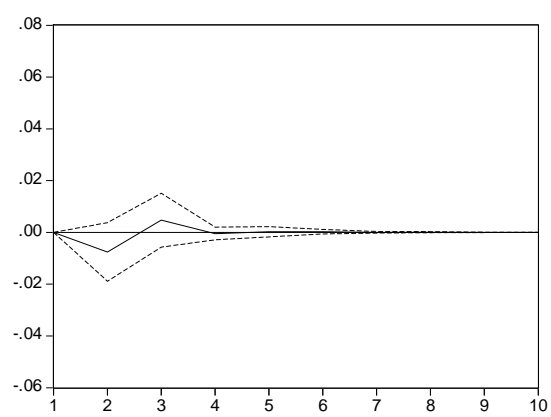


Figure 1b Response to Cholesky one SD innovation in exchange rate gap (gex)

Response of $\Delta \mathrm{r}$ : Czech Republic

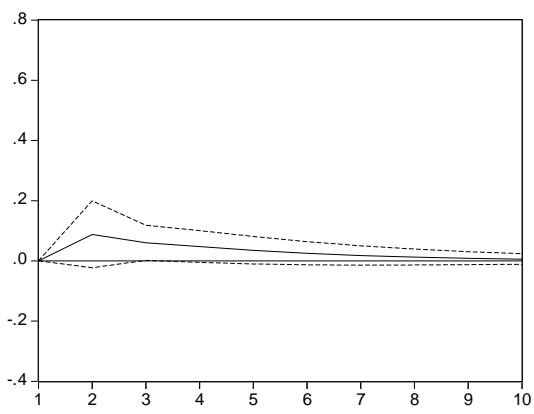

Response of $\Delta \mathrm{r}$ : Hungary

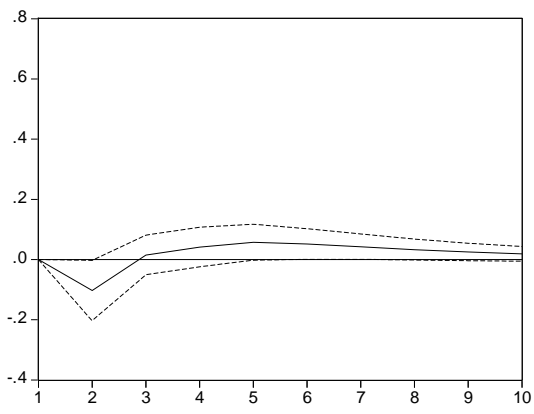

Response of $\Delta \mathrm{r}$ : Poland

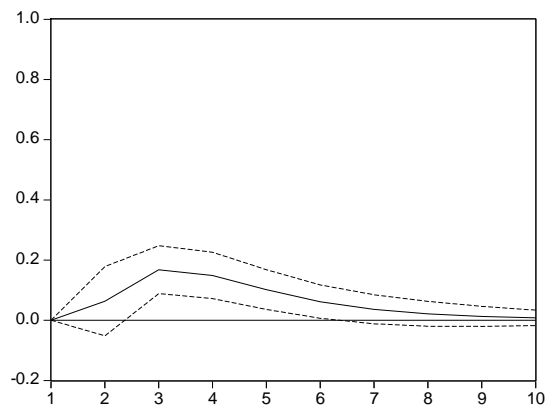

Response of $\Delta \mathrm{r}$ : Slovakia

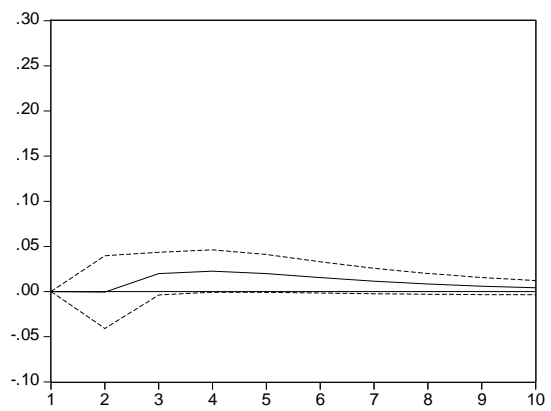

Response of $\Delta \mathrm{m}$ : Czech Republic

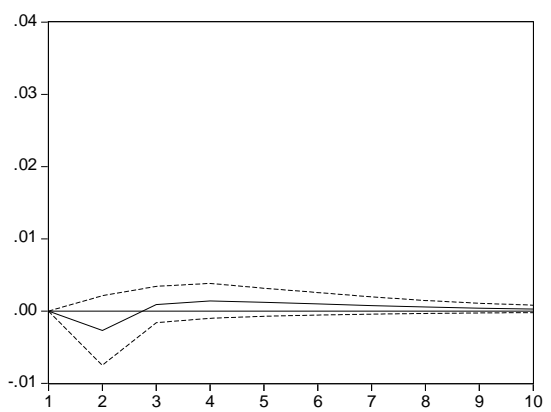

Response of $\Delta \mathrm{m}$ : Hungary

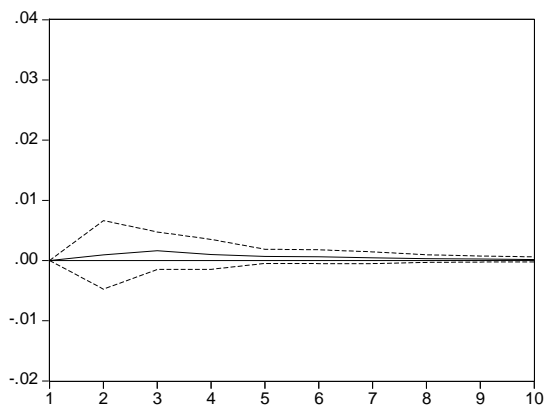

Response of $\Delta \mathrm{m}$ : Poland

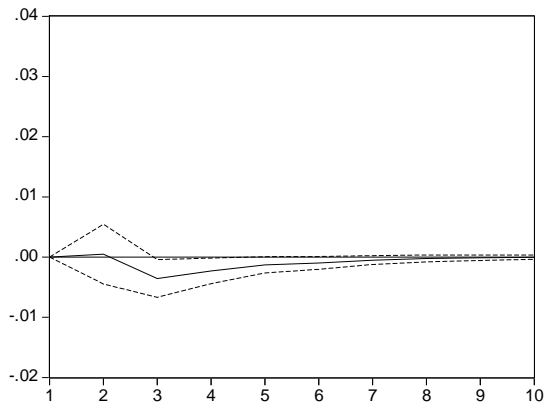

Response of $\Delta \mathrm{m}$ : Slovakia

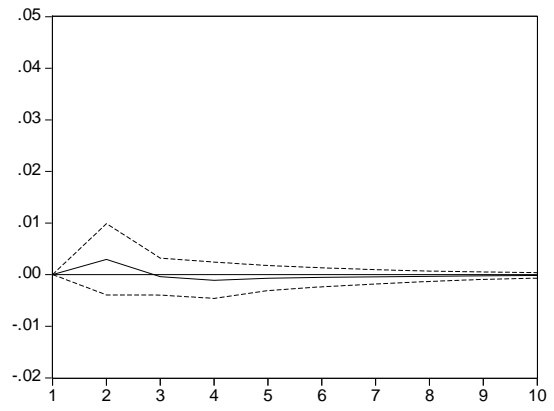


Figure 1b Response to Cholesky one SD innovation in exchange rate gap (gex) (to be continued)

Response of $\Delta \mathrm{r}$ : Slovenia

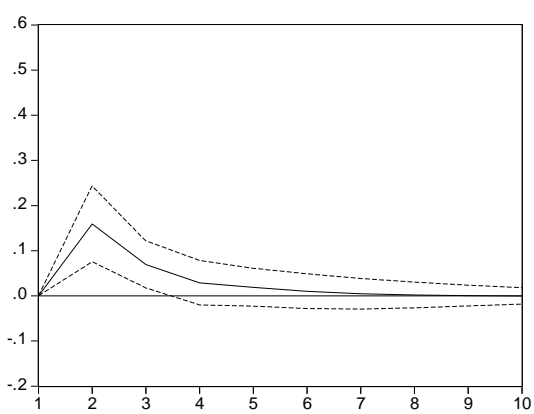

Response of $\Delta \mathrm{r}$ : Bulgraria

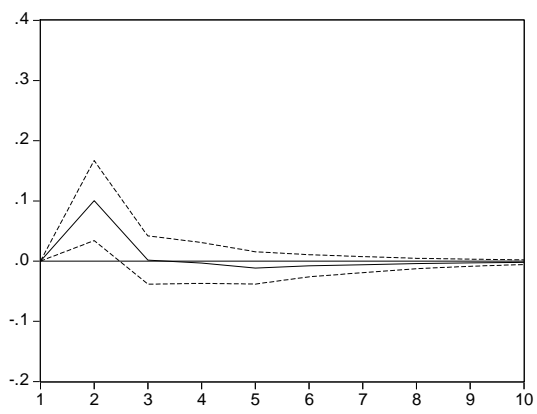

Response of $\Delta \mathrm{r}$ : Romania

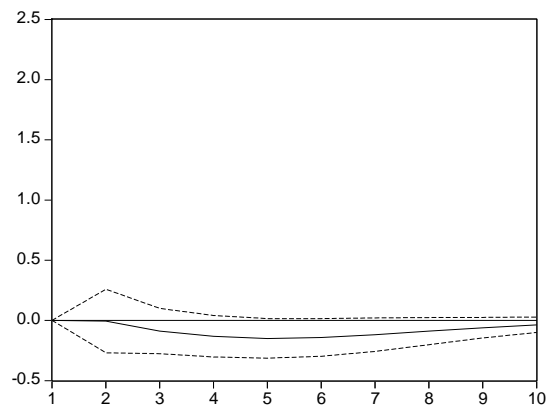

Response of $\Delta \mathrm{m}$ : Slovenia

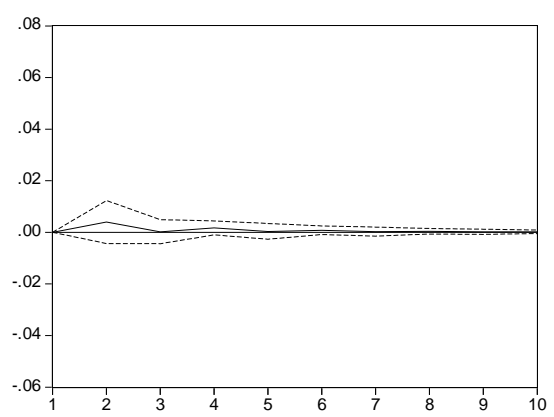

Response of $\Delta \mathrm{m}$ : Bulgaria

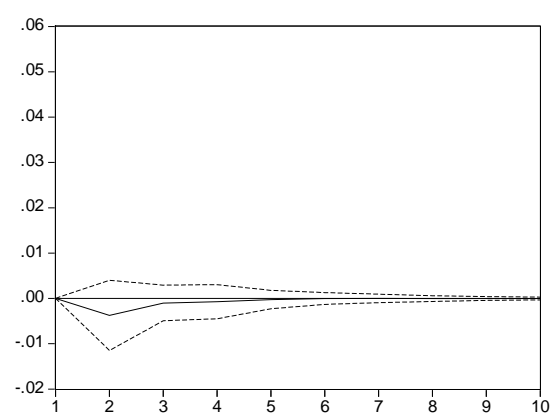

Response of $\Delta \mathrm{m}$ : Romania

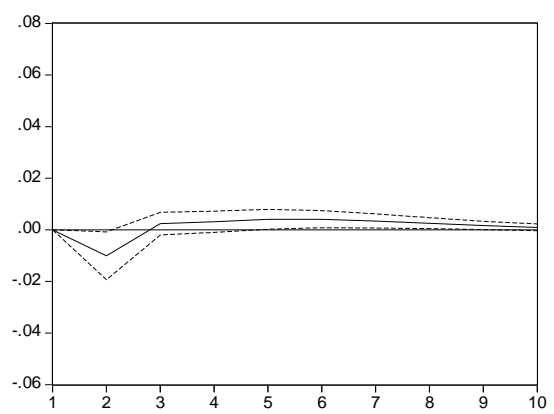

